Patricia A. Duncan

\title{
Novel Hermeneutics in the Greek Pseudo-Clementine Romance
}

[Roman-Hermeneutik in griechischen pseudoklementinischen Homilien.]

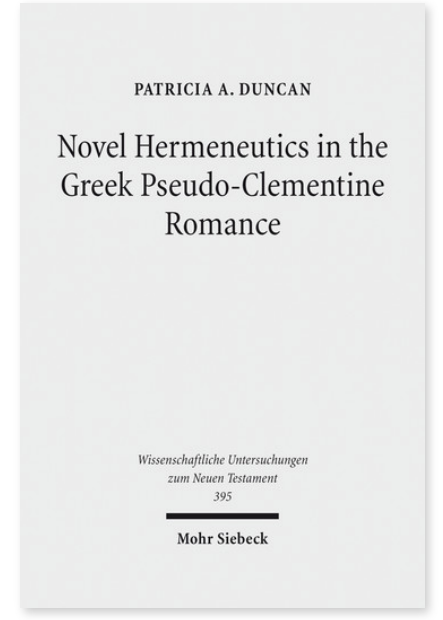

2017. XIV, 204 Seiten. WUNT I 395

ISBN 978-3-16-155584-8

DOI 10.1628/978-3-16-155584-8

eBook PDF $114,00 €$

ISBN 978-3-16-155265-6

Leinen $114,00 €$
Veröffentlicht auf Englisch.

Patricia A. Duncan untersucht den christlichen Roman aus dem 4. Jahrhundert, der traditionell als pseudoklementinische Homilien (hier jedoch als Klementia bezeichnet) bekannt ist, um zu zeigen, wie die ausgedehnte und komplexe Erzählung als rhetorisches Ganzes zusammenhängt und als Einführung des Lesers in eine neuartige, esoterische Vorstellung von den Ursprüngen des Christentums fungiert. Der Roman ist bekannt für seine auffällige Doktrin der »falschen Perikopen« in den Schriften der Juden, genauso wichtig ist jedoch die Art und Weise, wie er aus seinem Erzählgenre Nutzen zieht, um falsche Perikopen in den Evangelien des Neuen Testaments zu korrigieren. Der Schlüssel zu den Absichten des Romans ist die Konstruktion des Apostels Petrus als Hauptüberlieferer und autorisierter Deuter der Worte und Taten des wahren Propheten Jesus. Dieser Petrus präsentiert ein gesetzestreues, monotheistisches »Christentum«, welches quasi vollständig an die Religion der Anhänger Mose gekoppelt ist.

Patricia A. Duncan Born 1975; 2003 MDiv, University of Chicago; 2014 PhD, University of Chicago; currently Assistant Professor of Religion, AddRan College of Liberal Arts, Texas Christian University. https://orcid.org/0000-0002-6055-465X
Jetzt bestellen:

https://mohrsiebeck.com/buch/novel-hermeneutics-in-the-greek-pseudo-clementine-romance-9783161555848?no_cache=1 order@mohrsiebeck.com

Telefon: $+49(0) 7071-923-17$

Telefax: $+49(0) 7071-51104$ 